\title{
A survey on the awareness and knowledge about elective oocyte cryopreservation among unmarried women of reproductive age visiting a private fertility center
}

\author{
Yeon Hee Hong ${ }^{1,{ }^{*}}$, Jeong Woo Park ${ }^{2,{ }^{*}}$, Hyein $\mathrm{Kim}^{3}$, Seul Ki Kim ${ }^{1,4}$, Chang Woo Choo ${ }^{5}$, Byung Chul Jee ${ }^{1,4}$, \\ Chang Suk Suh ${ }^{3,4}$, Seok Hyun Kim ${ }^{3,4}$ \\ Department of Obstetrics and Gynecology, ${ }^{1}$ Seoul National University Bundang Hospital, Seongnam; ${ }^{2}$ Grace Women's Hospital, Goyang; ${ }^{3}$ Seoul \\ National University Hospital; ${ }^{4}$ Seoul National University College of Medicine; ${ }^{5}$ Seoul Maria Fertility Hospital, Seoul, Korea
}

\section{Objective}

The aim of this study was to investigate the level of awareness and knowledge regarding elective oocyte cryopreservation (OC) among unmarried women of reproductive age in Korea.

\section{Methods}

A survey was conducted among 86 women who visited a fertility preservation clinic for counseling about elective OC between December 2016 and May 2018. Participants were asked to fill out a questionnaire regarding their awareness and knowledge of fertility and OC.

\section{Results}

The questionnaire was completed by 71 women. Among them, $73 \%$ decided to undergo OC after counseling. The main reason for making this decision was that they wished to maintain their fertility in the future $(70.6 \%)$. Conversely, the high cost for the procedure was the main reason given by those who chose to forego this procedure. Regarding fertility and OC, the participants' knowledge was poor. Most women expected greater financial support from the government or from their place of employment.

\section{Conclusion}

This study demonstrated that the awareness and knowledge about elective $\mathrm{OC}$ were relatively poor among the female Korean population. These findings may help clinicians in better counselling of their patients.

Keywords: Cryopreservation; Oocytes; Fertility preservation; Surveys and questionnaires; Awareness

\section{Introduction}

There has been an increasing trend of delayed marriage and consequently, childbearing until the 30 s and 40 s, because of the increased role of women in social participation and contribution to economic growth. However, the risk of chromosomal abnormalities of oocytes rapidly increases around 35 years of age, resulting in a dramatic increase in the risk of infertility, miscarriage, high-risk pregnancy, and birth defects [1-3].
Received: 2019.05.29. Revised: 2019.07.25. Accepted: 2019.07.29. Corresponding author: Seul Ki Kim

Division of Reproductive Endocrinology \& Infertility, Department of Obstetrics and Gynecology, Seoul National University Bundang Hospital, 82 Gumi-ro 173beon-gil, Bundang-gu, Seongnam 13620, Korea

E-mail: drksk80@gmail.com

https://orcid.org/0000-0002-1647-6711

Chang Woo Choo

Department of Obstetrics and Gynecology, Seoul Maria Fertility Hospital, 20, Cheonho-daero, Dongdaemun-gu, Seoul 02586, Korea E-mail: mykeyfor@mariababy.com https://orcid.org/0000-0002-9565-8029

${ }^{\star}$ The first two authors contributed equally to this work.

Articles published in Obstet Gynecol Sci are open-access, distributed under the terms of the Creative Commons Attribution Non-Commercial License (http://creativecommons. org/licenses/by-nc/3.0/) which permits unrestricted non-commercial use, distribution, and reproduction in any medium, provided the original work is properly cited.

Copyright $\odot 2019$ Korean Society of Obstetrics and Gynecology 


\section{Obstetrics \& Gynecology Science}

Yeon Hee Hong, et al. Awareness about oocyte cryopreservation

In the past, the majority of fertility clinics offered oocyte cryopreservation (OC) mainly to women who were diagnosed with cancer and that underwent fertility impairing treatments as a consequence, such as chemotherapy or radiation [4]. However, due to recent trends many infertility clinics are now offering elective $\mathrm{OC}$ to accommodate women who are not ready to have children and wish to preserve their reproductive potential by delaying childbearing [5].

In 2012, the American Society for Reproductive Medicine (ASRM) Practice Committee announced that OC is no longer an experimental method [6]. Moreover, in 2018 the Ethics Committee of the ASRM concluded that elective $O C$ is an ethically permissible medical therapy, with the sole purpose to preserve reproductive potential of healthy women [7]. Although there has been a mounting interest in elective $\mathrm{OC}$ recently, the rate of women who actually pursue fertility preservation is relatively low, ranging between $3.1 \%$ and $19 \%$ $[8,9]$. The reason for the discrepancy between the level of interest and the rate of actual pursuit of $\mathrm{OC}$ remains unknown.

If gynecologists or other health care providers would like to provide competent counseling, it is important to identify women's knowledge level, as well as critical factors that influence their decision-making regarding fertility preservation, especially in unmarried and childless women. Clinicians should consider such factors because these can affect women's perception and actual decision to undergo elective OC. Until recently, only a few survey studies have assessed the general perception and knowledge concerning elective $\mathrm{OC}$ $[8,10]$. The factors affecting women's decisions to undergo elective $O C$ can vary widely depending on their racial and cultural backgrounds [11]. Because of this influence, each region should be surveyed and studied separately.

The aim of this study was to investigate the level of awareness and knowledge concerning elective $\mathrm{OC}$ among unmarried women of reproductive age visiting a private fertility center in Korea.

\section{Materials and methods}

\section{Study protocol}

The survey study consisted of a 30-item questionnaire which attempted to assess the degree of awareness and knowledge about $\mathrm{OC}$ in unmarried women of reproductive age. Women at the clinic who wanted to preserve oocytes for non-medical reasons, such as late marriage, were asked to fill out a questionnaire with their consent. The study protocol was approved by the Ethics Committee at Seoul Maria Fertility Hospital, Seoul, Republic of Korea (2016-002); informed consent was obtained from all study subjects.

\section{Participants}

All participants were recruited at Seoul Maria Fertility Hospital between December 2016 and May 2018. Women who wished to preserve their fertility for various social reasons, such as delaying childbearing, were deemed eligible for this study. The inclusion criteria were subjects aged between 20 and 45 years and subjects with no partner at the time of recruitment. For data analysis, we included women who answered "No" to the question "Have you ever heard of or interested in fertility preservation using egg freezing?". Additionally, we included those who said 'No' to the question "Do you wish to undergo egg freezing for the preservation of future fertility?" Two women who had previously undergone OC were excluded.

\section{The questionnaire}

The construction of the questionnaire was based on previous published studies [8] and translated into Korean before use (Supplementary Data 1).

\section{1) Demographics}

Study participants were asked to answer all questions about age, current marital status, history of divorce, number of children, age at the first childbirth, parity, professional activity, annual income, residential district, educational level, and religion.

\section{2) Willingness to get pregnant}

To evaluate their willingness to get pregnant, subjects had to answer 4 questions, which included their expected timing of conception in the coming years, the number of children that they wanted, their thoughts about the oldest fertile age, and their preference for multifetal gestations.

3) Recognition about oocyte cryopreservation and factors that affect a woman's decision-making in the utilization of fertility preservation by oocyte cryopreservation

The twelve-item questionnaire was used to identify women's 


\section{Obstetrics \& Gynecology Science}

Vol. 62, No. 6, 2019

awareness and knowledge of OC. Of these, 7 questions aimed to evaluate their awareness of $O C$ on a scale of 1 (not at all) to 5 (to a great extent), indicating the degree of relevance to the subjects. The remaining 5 questions were used to identify the factors influencing their decision to undergo elective OC.

\section{4) Knowledge about reproductive aging and oocyte cryopreservation}

Respondents had to answer 6 questions about the reproductive outcomes in women with advanced maternal age and the survival rate of post-thawing oocytes to assess their fertility awareness and knowledge about OC. The questions were constructed based on previously published studies [8], and translated into Korean.

\section{Results}

\section{Demographics}

A total of 86 women received the survey; of these, 15 who provided incomplete information were excluded. A final group of 71 completed the survey and were analyzed. The demographic characteristics of the study population, including age group, professional activity, annual income, educational level, and religion, are described in Table 1. The mean age was 37.0 years. The largest proportion of the respondents were professionals (27/71, 38\%), university graduates or higher $(63 / 71,89 \%)$, earners with an annual income of approximately 20,000-50,000 USD (20,000,000-50,000,000 Korean won) $(31 / 71,44 \%)$, and those with no religion (39/71, $55 \%)$.

\section{Awareness of oocyte cryopreservation}

Participants were asked to respond to 3 questions related to their awareness about $\mathrm{OC}$. The results are described in Fig. 1. Of the total respondents, 51 (71.8\%) responded that they decided to undergo OC. Of these 51 women, excluding 1 woman who did not answer this question, $48 \%$ of respondents indicated that the time interval from hearing about $\mathrm{OC}$ to deciding to receive OC was 6 months or less $(n=24 / 50)$ (Fig. 1A). Overall, this time frame was found to take 1 year or less for most of the women surveyed (66\%).

The second question regarded the reason for making the decision to undergo $O C$, and a plural response was allowed.
The responses are shown in Fig. 1B. The respondents most frequently reported that they wished to maintain their fertility in the future for when they attempt pregnancy $(70.6 \%$, $36 / 51$ ), followed by the response that they had no current partner and wanted a healthy baby by using good quality eggs in the future.

The third question was used to evaluate women's atti-

Table 1. Demographics of the study population $(n=71)$

\begin{tabular}{|c|c|}
\hline Demographic variables & $\begin{array}{l}\text { Distribution of the } \\
\text { respondents }\end{array}$ \\
\hline \multicolumn{2}{|l|}{ Age group (yr) } \\
\hline $20-24$ & $2(2.8)$ \\
\hline $25-29$ & $5(7.0)$ \\
\hline $30-34$ & $12(16.9)$ \\
\hline $35-39$ & $36(50.7)$ \\
\hline $40-45$ & $16(22.5)$ \\
\hline \multicolumn{2}{|l|}{ Occupation } \\
\hline Employee & $27(38.0)$ \\
\hline Self-employed & $9(12.7)$ \\
\hline Professional practice & $10(14.1)$ \\
\hline Teacher & $4(5.6)$ \\
\hline Student & $4(5.6)$ \\
\hline Public official & $3(4.2)$ \\
\hline Unemployed & $2(2.8)$ \\
\hline Others or non-response & $12(16.9)$ \\
\hline \multicolumn{2}{|c|}{ Annual income (1,000 Korean won unit) } \\
\hline$<10,000$ & 0 \\
\hline $10,000-20,000$ & $10(14.1)$ \\
\hline $20,000-50,000$ & $31(43.7)$ \\
\hline $50,000-100,000$ & $16(22.5)$ \\
\hline$>100,000$ & $7(9.9)$ \\
\hline Non-response & $7(9.9)$ \\
\hline \multicolumn{2}{|l|}{ Educational level } \\
\hline High school & $8(11.3)$ \\
\hline University graduate & $36(50.7)$ \\
\hline Postgraduate & $27(38.0)$ \\
\hline \multicolumn{2}{|l|}{ Religion } \\
\hline Protestantism & $17(23.9)$ \\
\hline Catholic & $12(16.9)$ \\
\hline Buddhism & $3(4.2)$ \\
\hline No religion & 39 (54.9) \\
\hline
\end{tabular}

Values are presented as number (\%). 


\section{Obstetrics \& Gynecology Science}

Yeon Hee Hong, et al. Awareness about oocyte cryopreservation

tudes towards oocyte donation after freezing their oocytes when they conceived naturally or when they decided not to attempt pregnancy anymore. The survey results (plural answers) are shown in Fig. 1C. Most women answered that they would donate to the infertile patients; $13 \%$ for family, $7 \%$ for relatives, $14 \%$ for friends, and $10 \%$ for anonymous persons. Most of the respondents $(61.8 \%, 60 / 97)$ expressed positive intent for oocyte donation to their family members, friends, anonymously to other people, or to research institutes.

\section{Distribution of women's knowledge related to fertility and oocyte cryopreservation}

Evaluation of background knowledge related to fertility and OC consisted of a 6-item, multiple-choice questionnaire. The responses of the participants are described in Table 2. The majority of respondents indicated the correct answer to the question, "At what age period is there a marked decrease in a woman's ability to become pregnant?"; however, for all other questions, most of the respondents answered incorrectly.

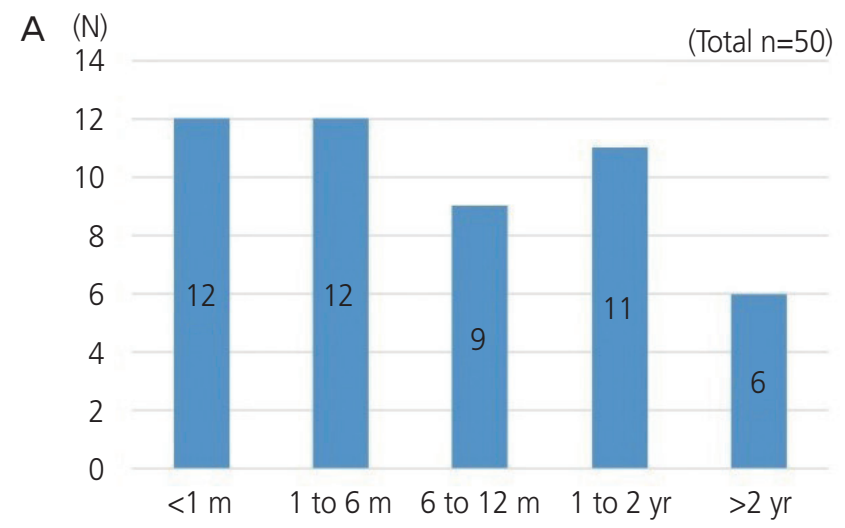

C (N) $=$ Family $\approx$ Relative $=$ Friends $\approx$ Anonymously

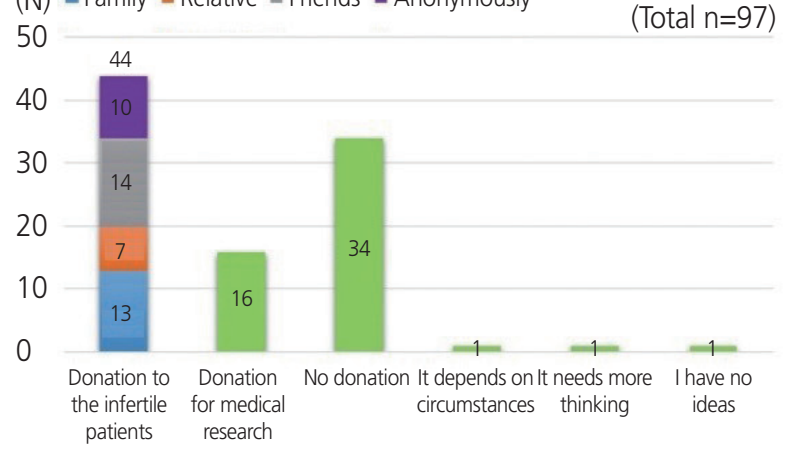

\section{Distribution of women's perception on fertility preservation issues}

Participants were asked to respond to 7 questions related to their perception on issues surrounding fertility preservation, using a 5-point scale (Table 3). In response to the question, "If a woman over 30 years of age is not ready to get married or to have a child, she should consider preserving her fertility through egg freezing", 43.7\% (31/71) gave affirmative answers. The 2 nd and 4 th questions were about the necessity for medical insurance or social security system to cover the costs for the procedure of freezing eggs. Of the total respondents $77 \%$ and $93 \%$, respectively, indicated that the costs for the procedure should be covered by medical insurance or a social security system, regardless of the reasons for undergoing the procedure. Moreover, almost all participants agreed that women facing fertility-impairing cancer treatment should be recommended to preserve their fertility using egg freezing. Of the total respondents, $61 \%$ answered positively in response to the question, "If a company supports the cost for freezing my eggs, I would like to delay pregnancy and work for a longer time.".

B

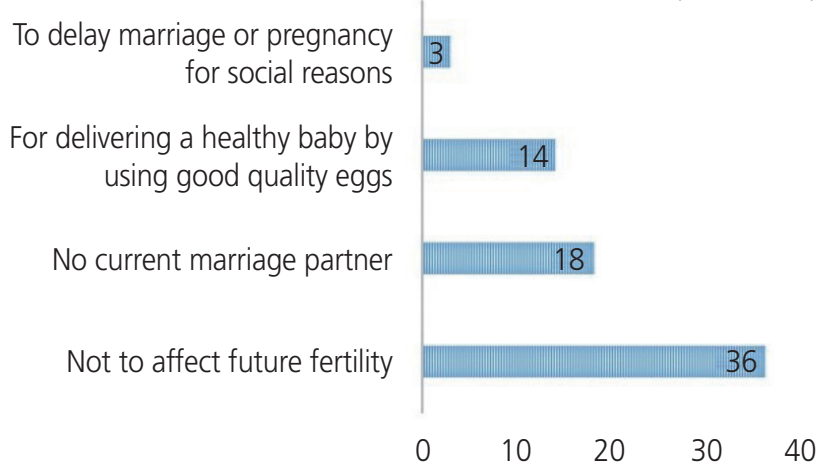

Fig. 1. Awareness of participants about oocyte cryopreservation. (A) Time interval between hearing about to the decision to execute oocyte cryopreservation; (B) Reason for the decision to execute oocyte cryopreservation (plural answers were allowed); (C) Attitudes of women towards oocyte donation (plural answers were allowed). 


\section{Obstetrics \& Gynecology Science}

Vol. 62, No. 6, 2019

\section{Discussion}

The findings of this survey study provide important insights into women's perception and attitudes about fertility preservation by OC. They also identify critical reasons for women's decision to undergo elective $O C$, and significant gaps in

Table 2. Distribution of women's knowledge related to reproduction and fertility and oocyte cryopreservation

\begin{tabular}{|c|c|c|c|c|c|}
\hline Question & 1 & 2 & 3 & 4 & 5 \\
\hline \multirow{2}{*}{$\begin{array}{l}\text { 1. If a woman between } 35 \text { to } 40 \text { years of age regularly has unprotected } \\
\text { intercourse during a period of year, how large is the chance that she } \\
\text { will become pregnant? (\%) }\end{array}$} & $20-29 \%$ & $30-39 \%$ & $40-49 \%$ & $50-59 \%{ }^{a)}$ & $\geq 60 \%$ \\
\hline & 42.3 & 25.4 & 21.1 & 7.0 & 4.2 \\
\hline \multirow{2}{*}{$\begin{array}{l}\text { 2. At what age period is there a marked decrease in woman's ability to } \\
\text { become pregnant? }(\%)\end{array}$} & $15-24 \mathrm{yr}$ & $25-29 \mathrm{yr}$ & $30-34 \mathrm{yr}$ & $35-39 y r^{a)}$ & $40-50 \mathrm{yr}$ \\
\hline & 0 & 0 & 16.9 & 71.8 & 11.3 \\
\hline \multirow{2}{*}{$\begin{array}{l}\text { 3. What is the chance of miscarriage in a pregnant woman at the age } \\
\text { of } 40 \text { years? }(\%)\end{array}$} & $<1 \%$ & $1-10 \%$ & $11-20 \%$ & $21-30 \%{ }^{a)}$ & $>30 \%$ \\
\hline & 0 & 11.3 & 28.2 & 33.8 & 26.8 \\
\hline \multirow{2}{*}{$\begin{array}{l}\text { 4. What is the chance of delivering a child with Down syndrome in a } \\
\text { pregnant woman at the age of } 40 \text { years? }(\%)\end{array}$} & $0.01 \%$ & $0.1 \%$ & $1-2 \%{ }^{\text {a) }}$ & $5 \%$ & $>10 \%$ \\
\hline & 7.0 & 14.1 & 23.9 & 28.2 & 26.8 \\
\hline \multirow{2}{*}{$\begin{array}{l}\text { 5. What is the chance of pregnancy after one IVF treatment at an age } \\
\text { between } 40 \text { and } 43 \text { years? (\%) }\end{array}$} & $<15 \%$ & $16-25 \%$ a) & $26-35 \%$ & $36-45 \%$ & $>45 \%$ \\
\hline & 26.8 & 22.5 & 23.9 & 15.5 & 11.3 \\
\hline \multirow{2}{*}{$\begin{array}{l}\text { 6. What is the survival rate of frozen eggs after defrosting process in a } \\
\text { woman with less than } 35 \text { years of age? (\%) }\end{array}$} & $20-40 \%$ & $40-60 \%$ & $60-80 \%$ & $80-95 \%{ }^{a)}$ & $>95 \%$ \\
\hline & 15.5 & 23.9 & 15.5 & 29.6 & 15.5 \\
\hline
\end{tabular}

IVF, in vitro fertilization.

a)Indicates the correct answer according to published data.

Table 3. Distribution of women's perception on fertility preservation issues

\begin{tabular}{|c|c|c|c|c|c|c|}
\hline Perception on fertility preservation issues & $\begin{array}{l}\text { Definitely } \\
\text { not (1) }\end{array}$ & $\begin{array}{l}\text { Probably } \\
\text { not (2) }\end{array}$ & $\begin{array}{c}\text { Uncertain } \\
\text { (3) }\end{array}$ & $\begin{array}{l}\text { Probably } \\
\text { (4) }\end{array}$ & $\begin{array}{c}\text { Definitely } \\
\text { (5) }\end{array}$ & $\begin{array}{l}\text { 5-point } \\
\text { scale }\end{array}$ \\
\hline $\begin{array}{l}\text { 1. If a woman over } 30 \text { years of age is not ready to get } \\
\text { married or have a child, she should consider preserving } \\
\text { her fertility through egg freezing. }\end{array}$ & 9.9 & 5.6 & 40.8 & 35.2 & 8.5 & $3.3 \pm 1.0$ \\
\hline $\begin{array}{l}\text { 2. If a woman is not ready to be pregnant and wishes to } \\
\text { undergo egg freezing for her fertility preservation, the } \\
\text { costs for the procedure should be covered by medical } \\
\text { insurance or social security system. }\end{array}$ & 1.4 & 5.6 & 15.4 & 43.6 & 33.8 & $4.0 \pm 0.9$ \\
\hline $\begin{array}{l}\text { 3. For a woman facing fertility-impairing cancer } \\
\text { treatment, egg freezing is recommended to preserve } \\
\text { her future fertility. }\end{array}$ & 0 & 0 & 2.8 & 14.1 & 83.1 & $4.8 \pm 0.5$ \\
\hline $\begin{array}{l}\text { 4. For a woman facing fertility-impairing cancer } \\
\text { treatment, the costs for the procedure should be } \\
\text { covered by medical insurance or social security system. }\end{array}$ & 0 & 4.2 & 2.8 & 25.4 & 67.6 & $4.6 \pm 0.8$ \\
\hline $\begin{array}{l}\text { 5. Information about egg freezing as a part of regular } \\
\text { health care should be routinely provided by physicians } \\
\text { to women of childbearing age. }\end{array}$ & 1.4 & 1.4 & 15.5 & 36.6 & 45.1 & $4.2 \pm 0.9$ \\
\hline $\begin{array}{l}\text { 6. If a company supports the cost of freezing my eggs, I } \\
\text { would like to delay pregnancy and work for a longer } \\
\text { time. }\end{array}$ & 2.8 & 16.9 & 19.7 & 28.2 & 32.4 & $3.7 \pm 1.2$ \\
\hline $\begin{array}{l}\text { 7. If I couldn't afford to freeze my eggs, I would consider } \\
\text { asking for financial support from a parent or family } \\
\text { member to pay for this procedure. }\end{array}$ & 5.6 & 12.6 & 25.4 & 28.2 & 28.2 & $3.6 \pm 1.2$ \\
\hline
\end{tabular}

Values are presented as percentage (\%) or mean \pm standard deviation. 


\section{Obstetrics \& Gynecology Science}

Yeon Hee Hong, et al. Awareness about oocyte cryopreservation

women's knowledge about female reproduction, reproductive outcomes of those with advanced maternal age, and survival rates of post-thawing oocytes.

As shown in the result section, $71.8 \%$ of the respondents said that they would undergo elective OC. Contrary to our result, in Tan et al.'s study [11] of Singaporean female medical students, only $26.4 \%$ of the respondents said they would opt for elective OC, while $54.3 \%$ were unsure Similarly, only $3.1 \%$ of surveyed population were positive for elective OC, while $45.1 \%$ were unsure and $51.8 \%$ answered no in Belgium group [8]. These differences can be said to be a unique phenomenon of Korea in comparison to other countries, and women should be appropriately advised to meet the needs of elective OC.

With respect to maternal age, the largest proportion of the respondents who visited our fertility preservation clinic for OC were between the ages of 35 to 39 years (50.7\%), followed by 40 to 45 years (22\%). Interestingly, as a result of the questionnaire regarding women's knowledge related to fertility and OC, most women were much less aware of the decline in age-adjusted fertility. A recent report by Cobo et al. [12] showed the survival rate of frozen-thawed oocytes and the cumulative live birth rate of women who had undergone elective OC for non-oncologic reasons. When women consumed 8 to 10 oocytes, the cumulative live birth rates in the group of women aged 35 years or younger at the time of vitrification were twice as high as those older than 35 years. At present, the age limit generally used for elective $O C$ is suggested to be 38 [13]. Taken together, this indicates that clinicians should recommend that women be encouraged to undergo $\mathrm{OC}$ and try pregnancy at a younger age for the best chance of having a healthy baby.

In terms of factors that may influence the decision to undergo OC as a means of fertility preservation, our result was similar to those found by Stoop et al. [8]; the major concerns were the viability of frozen-thawed eggs and the health risks to themselves and their future children. Although a minority of women $(n=9)$ were unwilling to undergo the procedure, these negative perceptions could possibly be overcome by evidence-based counseling.

Moreover, the survey results demonstrate the women's desire and request for financial support to receive $O C$, regardless of the reason for undergoing the procedure. Interestingly, given that a company may cover the cost for procedures including OC, the score of women that responded that they would like to postpone pregnancy to build their career was high (3.7 \pm 1.2$)$. Actually, a considerable proportion of women who decided to undergo OC were employees with high income and high educational level; this may be attributable to the high cost of the procedure. With the expansion of governmental and institutional support, it may be possible to meet the demand of women who want to preserve their fertility, potentially addressing the concerns of low fertility and an aging society.

Some previous studies have reported women's opinions about OC or factors that lead them to pursue OC $[9,14-16]$. Of these, 1 study was conducted among Korean women; however, this study only focused on the decision-making process for undergoing OC [17]. Our study is different from previous studies in that it firstly examined the perception reflecting the actual knowledge level about OC, and also considered the socioeconomic factors among Korean women. Furthermore, this study performed analysis using other measurement scales.

The fact that the questionnaire was conducted for women who visited the private fertility clinic rather than for the whole Korean female population may be a limit, and it may be necessary to conduct research on general population in the future.

In conclusion, this study shows that Korean women's awareness and knowledge regarding elective $O C$ are relatively low. However, the level of interest in the procedure seems to be high. There seems to be a large discrepancy present that needs to be resolved to improve the level of real knowledge about elective OC. Clinicians should consider these points when counseling patients.

\section{Conflict of interest}

No potential conflict of interest relevant to this article was reported.

\section{Ethical approval}

The study protocol was approved by the Ethics Committee at Seoul Maria Fertility Hospital, Seoul, Republic of Korea (2016-002). 


\section{Obstetrics \& Gynecology Science}

Vol. 62, No. 6, 2019

\section{Patient consent}

Informed consent was obtained from all study subjects.

\section{Supplementary material}

Supplementary Data 1 associated with this article can be found online at https://doi.org/10.5468/ogs.2019.62.6.438.

\section{References}

1. Herbert M, Kalleas D, Cooney D, Lamb M, Lister L. Meiosis and maternal aging: insights from aneuploid oocytes and trisomy births. Cold Spring Harb Perspect Biol 2015; 7:a017970.

2. Pellestor F, Andréo B, Arnal F, Humeau C, Demaille J. Maternal aging and chromosomal abnormalities: new data drawn from in vitro unfertilized human oocytes. Hum Genet 2003;112:195-203.

3. Battaglia DE, Goodwin P, Klein NA, Soules MR. Influence of maternal age on meiotic spindle assembly in oocytes from naturally cycling women. Hum Reprod 1996;11:2217-22.

4. Cobo A, Garcia-Velasco JA, Domingo J, Remohí J, Pellicer A. Is vitrification of oocytes useful for fertility preservation for age-related fertility decline and in cancer patients? Fertil Steril 2013;99:1485-95.

5. Rudick B, Opper N, Paulson R, Bendikson K, Chung $K$. The status of oocyte cryopreservation in the United States. Fertil Steril 2010;94:2642-6.

6. Practice Committees of American Society for Reproductive Medicine; Society for Assisted Reproductive Technology. Mature oocyte cryopreservation: a guideline. Fertil Steril 2013;99:37-43.

7. Ethics Committee of the American Society for Reproductive Medicine. Planned oocyte cryopreservation for women seeking to preserve future reproductive potential: an Ethics Committee opinion. Fertil Steril
2018;110:1022-8.

8. Stoop D, Nekkebroeck J, Devroey P. A survey on the intentions and attitudes towards oocyte cryopreservation for non-medical reasons among women of reproductive age. Hum Reprod 2011;26:655-61.

9. Lallemant C, Vassard D, Nyboe Andersen A, Schmidt L, Macklon N. Medical and social egg freezing: internetbased survey of knowledge and attitudes among women in Denmark and the UK. Acta Obstet Gynecol Scand 2016;95:1402-10.

10. Daniluk JC, Koert E. Childless women's beliefs and knowledge about oocyte freezing for social and medical reasons. Hum Reprod 2016;31:2313-20.

11. Tan SQ, Tan AW, Lau MS, Tan HH, Nadarajah S. Social oocyte freezing: a survey among Singaporean female medical students. J Obstet Gynaecol Res 2014;40:134552.

12. Cobo A, García-Velasco JA, Coello A, Domingo J, Pellicer A, Remohí J. Oocyte vitrification as an efficient option for elective fertility preservation. Fertil Steril 2016;105:755-764.e8.

13. Cil AP, Bang H, Oktay K. Age-specific probability of live birth with oocyte cryopreservation: an individual patient data meta-analysis. Fertil Steril 2013;100:492-9.e3.

14. Milman LW, Senapati S, Sammel MD, Cameron KD, Gracia C. Assessing reproductive choices of women and the likelihood of oocyte cryopreservation in the era of elective oocyte freezing. Fertil Steril 2017;107:1214-1222. e3.

15. Hodes-Wertz B, Druckenmiller S, Smith M, Noyes N. What do reproductive-age women who undergo oocyte cryopreservation think about the process as a means to preserve fertility? Fertil Steril 2013;100:1343-9.

16. Ter Keurst A, Boivin J, Gameiro S. Women's intentions to use fertility preservation to prevent age-related fertility decline. Reprod Biomed Online 2016;32:121-31.

17. Kim R, Yoon TK, Kang IS, Koong MK, Kim YS, Kim MJ, et al. Decision making processes of women who seek elective oocyte cryopreservation. J Assist Reprod Genet 2018;35:1623-30. 